\title{
A unique computed tomographic finding: Dissection? Congenital structure? Artifact? New entity?-Significance in diagnosis of the "intra-aortic chord"
}

\author{
Tetsuya Fukuda, $\mathrm{MD}, \mathrm{PhD},{ }^{\mathrm{a}}$ and Soichiro Kitamura, $\mathrm{MD}, \mathrm{PhD}^{\mathrm{b}}$
}

\author{
From the ${ }^{a}$ Department of Radiology, National Cerebral and Cardiovascular Center, Osaka, Japan; and the \\ ${ }^{\mathrm{b}}$ National Cerebral and Cardiovascular Center, Osaka, Japan. \\ Disclosures: Authors have nothing to disclose with regard to commercial support. \\ Received for publication Feb 22, 2018; accepted for publication Feb 23, 2018; available ahead of print March 20, \\ 2018. \\ Address for reprints: Soichiro Kitamura, MD, PhD, National Cerebral and Cardiovascular Center, 5-7-1, Fujish- \\ irodai, Suita City, Osaka 565-8565, Japan (E-mail: skitamur@ncvc.go.jp). \\ J Thorac Cardiovasc Surg 2018; 156:357 \\ $0022-5223 / \$ 36.00$ \\ Copyright (C) 2018 by The American Association for Thoracic Surgery \\ https://doi.org/10.1016/j.jtcvs.2018.02.061
}

Precise diagnosis of Stanford type A aortic dissection is crucial and time sensitive, especially in emergency cases. Diagnostic procedures have been conducted by computed tomographic (CT) scan, ultrasonography, or both. ${ }^{1}$ Diagnosis of type A dissection is sometimes difficult, however, because many unique types of dissection-such as localized small dissection, retrograde dissection, or circumferential dissection, called intimointimal intussusception ${ }^{2}$ - have been reported. Moreover, in cases of dissection, CT scans a few days after the onset sometimes show the dynamic morphologic changes of a small ulcer or a flaplike lesion, which annoys physicians attempting the accurate diagnosis of aortic dissection. In the case reported in this issue of the Journal by Rachid and colleagues, ${ }^{3}$ no significant change was noted on the follow-up CT scan.

In addition, various other facts complicate the diagnosis of thoracic aortic disease. Without electrocardiographic gating, motion artifact caused by aortic compliance and cardiac motion resembles the intimal flap to be seen in the left anterior and posterior right margin of the ascending aorta. ${ }^{4}$ In the report of Rachid and colleagues, ${ }^{3}$ this intra-aortic chord showed an atypical image as a motion artifact and clearly demonstrated on volume-rendering 3-dimensional imaging a unique linear structure, somewhat of a cylindric tube in structure, traversing the aortic wall to the opposite site of the wall and measuring less than $5 \mathrm{~cm}$ in length and less than $5 \mathrm{~mm}$ in diameter. This chord or microtube traversing inside the aorta may be derived from a congenital tissue remnant, scar tissue, or new forms of chronic dissection or neoplasm. Unfortunately, the pathologic finding of this chord remains unknown, because this patient did not undergo a surgical procedure or biopsy of the chord, which is a limitation of the article. In addition, Rachid and colleagues $^{3}$ could not define the final strategy, whether this chord could be left untouched conservatively or needed

\section{References} 446-8. $569-72$.

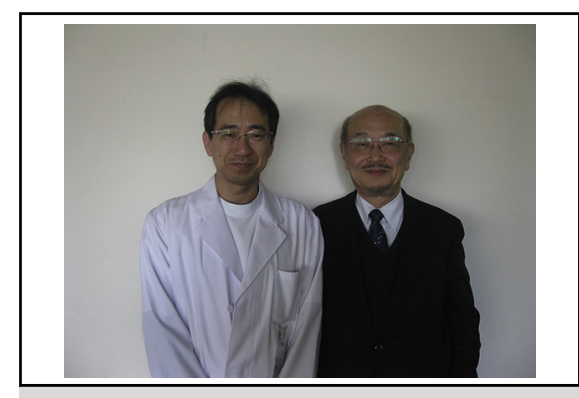

Tetsuya Fukuda, MD, PhD (left), and Soichiro Kitamura, MD, PhD (right).

Central Message

Especially in emergency cases, this article may help physicians to eliminate misleading treatment when aortic dissection is suspected on computed tomographic scan, even if clinical presentations are atypical.

See Article page 355 .

treatment such as anticoagulation, antiplatelet therapy, biopsy, or resection.

This article may provide physicians with an option to eliminate misinterpretation when acute aortic syndrome is suspected on CT scan or ultrasonography, even if the clinical course of the patients is atypical for the disease. The microtube structure traversing inside the aortic lumen, clearly demonstrated on 3-dimensional CT images, has not been reported previously, and we certainly welcome comments or similar images from readers who find or have found such a structure. Finally, we are interested in the genesis of this rare structure and hope that Rachid and colleagues ${ }^{3}$ let us know when they find out exactly what it is.

1. Pare JR, Liu R, Moore CL, Sherban T, Kelleher MS Jr, Thomas S, et al. Emergency physician focused cardiac ultrasound improves diagnosis of ascending aortic dissection. Am J Emerg Med. 2016;34:486-92.

2. Hillemanns A, Moller-Hartmann W, Miche E, Gleichmann U, Reinbold WD Circular dissection of the ascending aorta with intimo-intimal invagination. CT diagnosis of a rare form of aortic dissection [in German]. Radiologe. 1996;36:

3. Rachid Z, Arshid A, Jean-Marc A. Intra-aortic chord: a new entity? J Thorac Cardiovasc Surg. 2018;156:355-6.

4. Duvernoy O, Coulden R, Ytterberg C. Aortic motion: a potential pitfall in CT imaging of dissection in the ascending aorta. J Comput Assist Tomogr. 1995;19: 